\title{
ASPECT - a CASE-Tool for Control Functions Originating from Mechanical Layout
}

\author{
T. Brandl, R. Lutz, J. Reichenbächer \\ Institut für Steuerungstechnik der Werkzeugmaschinen und \\ Fertigungseinrichtungen, Universität Stuttgart \\ Seidenstr. 36 \\ 70174 Stuttgart \\ Germany \\ Tel.: ++49-711-121-2420 \\ FAX: ++49-711-121-2413 \\ thomas.brandl@isw.uni-stuttgart.de \\ rainer.lutz@isw.uni-stuttgart.de
}

\begin{abstract}
The systematic design of control software requires exchange of information between the software development department and other departments of an enterprise (e.g. project planning and mechanical design). For this purpose neither construction plans nor program listings are suitable description forms. In this paper three design levels and the related description forms are introduced. Thus a common information base shall be provided to all experts who are involved in an automation project. Step by step this information base may be detailed until it is possible to generate the code for a controller by a compiler automatically. Special respect is given on the reuse of design objects. For the efficient application of the proposed method the CASE-Tool prototype ASPECT has been developed at the Institute for Control Technology at the University of Stuttgart.
\end{abstract}

\section{Keywords}

Control software, software design methods, reuse, CASE-Tool 


\section{INTRODUCTION}

The present development of control software is characterized by increasingly complex requirements in regard to functionality, cost and quality. Control software, once only an "accessory" of electrical machine design, has now become an indispensable part of the final product, the "machine".

In the past the essential task was the programming of binary logic as a substitute for an relais control. Now, various additional tasks are to be solved, as for example diagnosis and monitoring functions, communication, man machine interfaces and data processing like tool management or machine data acquisition. These requirements cannot be met with traditional approaches and new techniques are required. This paper will show how control software development can be improved and which methods and tools are needed for this improvement.

\section{PROBLEMS AND GOALS}

The current process for developing control software is characterized by a strictly sequential succession of machine design tasks (Pritschow, u.a., 1994). Little exchange of information happens between the departments involved (Fig. 1). A lot of information (which is important later for the programming) is generated at an early phase of the project e.g. as a requirement specification or a submission to the customer made by the project planning department.

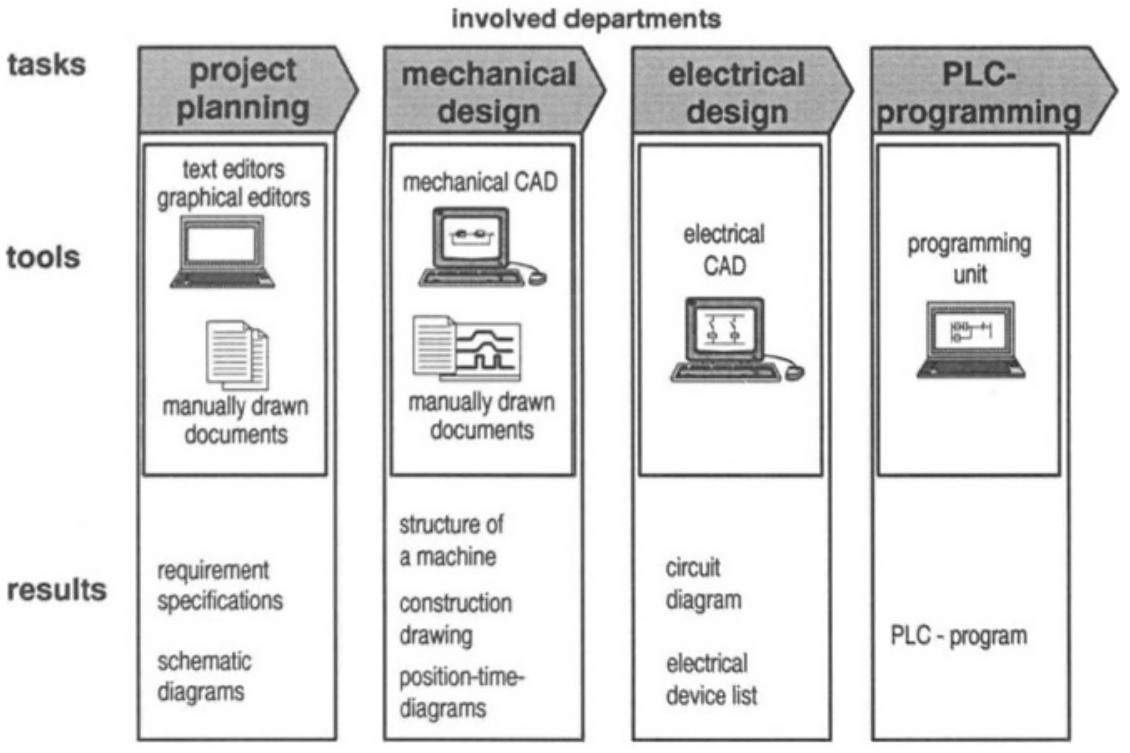

Figure 1 Typical sequence of project processing. (104 339e) 
Usually, computer-aided tools are applied, as e.g. mechanical or electrical CAD. Since it is impossible to exchange logical data between the different tools through suitable interfaces, each tool represents an isolated solution in regard to a specific area. Consequently, a great amount of data has to be entered repeatedly which results in increased work and a higher error rate.

In addition, these data isolated solutions impede an efficient cross-departmental application of re-usable design solutions and machine modifications. Therefore, reuse is only possible in specific departments; there it is executed at a growing rate. But this means that a minimal modification made in the mechanical design department may result in considerable modifications and adaptations of the control program.

In regard to cross-departmental information exchange, the question always arises: Which presentations and describing forms are most apt? It is very important to create a common communication basis (Storr u.a., 1994) for the staff involved. Not every document currently used is suitable for this purpose: a construction engineer will not know how to use an instruction list program, just like an PLC programmer will not derive benefits from the details of a technical drawing.

The customer driven necessity to change from one controller vendor to the product of another one usually requires a re-programming. The reuse of already developed and tested program modules is not possible in this case. Even the standardization of programming languages according to IEC 1131-3 (N.N., IEC 1131-3) did not improve this, because this standard does not include portability specifications.

Along with the actual development, the preparation of the technical documentation determines the elapsed time of a project. Information from the individual departments are usually collected and made into a document after the technical development is finished. The primary purpose of this is to make comprehensive information available to the service and maintenance staff. An accurate preparation of the documents is also important in regard to product liability or CE certification.

The above mentioned problems could be solved by the following measures:

Improving software quality by

- continuously proceeding from the start of the project to the commissioning,

- application of widely understood methods for the design of control software,

- increased re-use of already generated software design and modules and

- developing device-independent designs and programs.

Shortening of the elapsed project time by

- parallel project development by means of early information transfer between departments,

- preparing the documentation along with the development,

- automated generation of program code and

- application of one or more suitable computer-aided tools.

\section{REDUCED TIME FOR CONTROL SOFTWARE DEVELOPMENT}

Reduced development time for control software must allow in particular for the transfer of information at an early stage (Weck, Kohring, 1991). Here it is useful to provide different 
categories and to assign these categories specific functions. An extensive analysis leads to three design levels (Storr, u.a., 1994; Herrscher, Grimm, Storr, Reichenbächer, 1991)

- general description (design level 1)

- functional description (design level 2) and

- detailed description (design level 3).

Fig. 2 shows which departments in the different levels generate the descriptions and which departments use them.

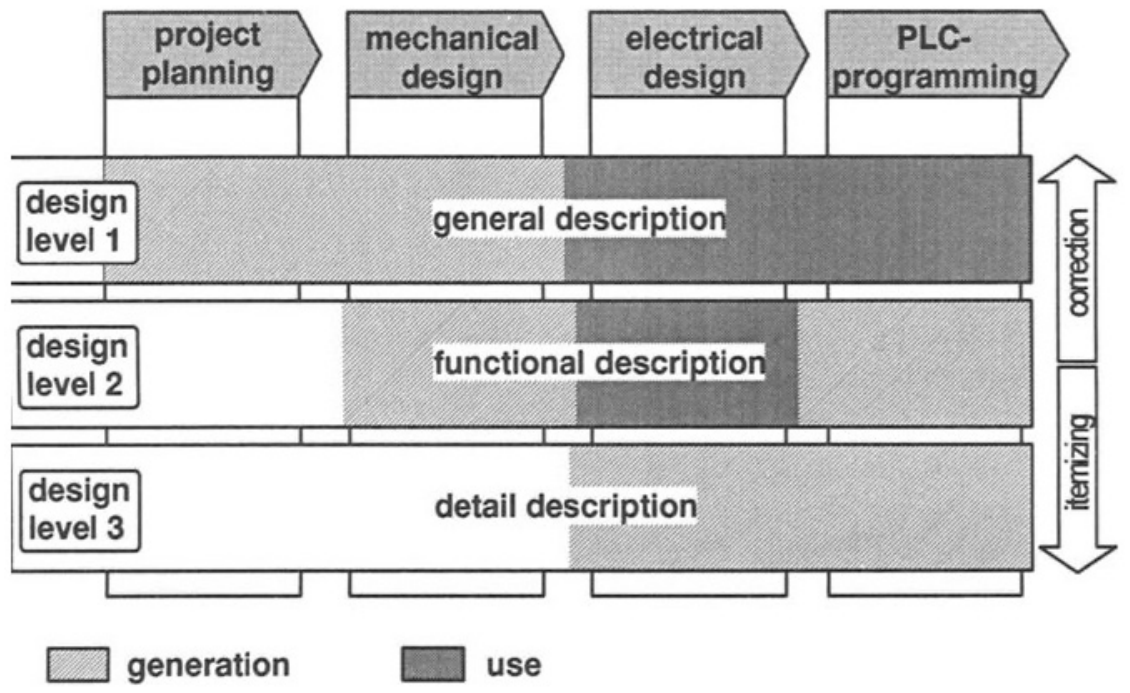

Figure 2 Design levels and description forms (104 340e)

General descriptions are mainly used for the early structuring of a machine or system, e.g. during the project planning phase or in the beginning of the mechanical design. Functions and mutual dependencies are illustrated in an abstract form.

The purpose of functional descriptions is to break down the functions that first, in the general descriptions, have been displayed abstractly, in order to fulfill the technical requirements.

Detailed descriptions give more information about all additional attributes of the elements used in the other design levels, besides just structure and function. Such information may be measurements, identifiers, cross references, connected loads etc.

By introducing defined structuring levels, we facilitate the modularization of the entire machine function and functional descriptions and design methods for control software. Thus the functions to be implemented can be described long before technical solutions are detailed. So it is passible

- to provide functional information at an early time and

- cross-departmentally aim at applying standardized solutions. 
Early data transfer is, at the same time, a necessary premise for parallel representation of the project work (simultaneous engineering). Appropriate methods for describing the functionally oriented structure and for the software design are presented in the following chapter.

\section{GENERAL DESCRIPTIONS AND FUNCTIONAL DESCRIPTIONS}

Suitable methods for supporting a parallel and cross-departmental information exchange in machine tool builder enterprises require a view of the problem that differs from the generally accepted views of today which are specific to particular departments. This means, for example, that functionality of a control system is not necessarily understood as a PLC-program for a specific controller. First there has to be a rather exact design for the control system, in which the functionality required (and later to be implemented) can be recognized by other participants of the project.

The layout of an installation is determined by mechanical design engineers. Therefore, it is convenient if the design objects which the control software engineer uses are closely related to the design objects of the mechanical engineer. Only if both experts agree for which parts of an installation already existing design objects are to be applied; can efficient reuse be possible.

At the design level of general descriptions, an expanded technology scheme can be used for this purpose, which differentiates design objects and contains a coarse geometric representation (Fig. 3). Design objects incorporate function units, function groups, actuators, sensors, operator control elements etc. as well as the interdependencies between them. Function units and function groups (in the following called function objects) can be detailed or combined so that any complex structure can be built. The design engineer can specify the behaviour of each function object by means of functional descriptions. The definition of clearly separated design objects results in

- unified structuring of a machine or a system,

- simple generation of modules and consequently easier reuse,

- clear function specification

- possibility to describe mutual dependencies and relations and

- high comprehensibility.

As a next step, by using the descriptions of design level 2 , it is necessary to add formal definitions to the design objects. This applies, as a rule, to function units and groups. Design objects like actuators and sensors are not further detailed. The relationships between the function units should also be described, since they represent the data exchange through interfaces of the function units. 


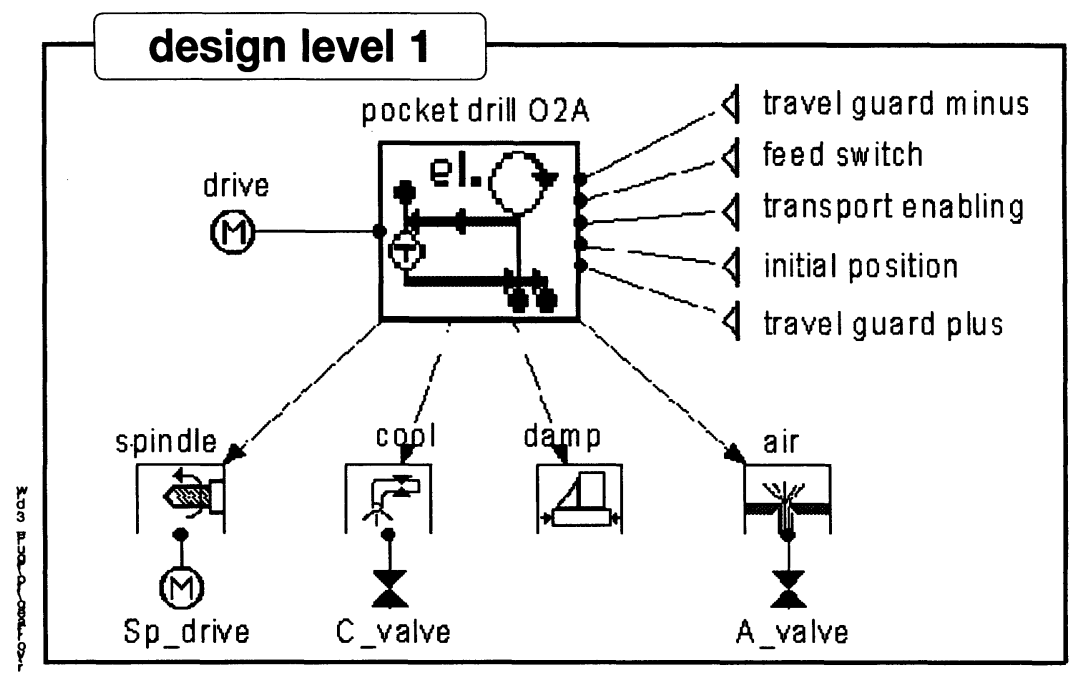

Figure 3 Example of an expanded technology scheme (104 341e)

Suitable descriptions (Pritschow, u.a., 1988) for logical dependencies - especially because of the graphical representation - include sequential function charts, Petri nets and state graphs. Signal curves according to VDI 3260 (VDI-Richtlinie 3260, 1977) describe more timeoriented interrelations.

State graphs (Fig. 4) (Fleckenstein, 1987; Otto, 1992) are examined closer in this book in the paper "State Diagrams - A New Programming Method for Programmable Logic Controllers". They can be used for describing function units and function groups formally and up to the code generation stage. State graphs are intentionally device-independent and easy to understand in order to enable different departments of an enterprise to use them. Nevertheless, they can be used to directly generate control programs - a feature that is required for continuity. For this purpose the description of all design objects contained in the general description must be completed. In detail this means

- complete state graphs for all function units and groups and

- sufficiently detailed specifications of the components (addresses, data types, etc.)

Thus the code generation for any type of controller is possible and also easy to automate after the details have been specified in design level 3. The I/O-addresses of controller signals are such a detail, for example. Fig. 5 shows our concept and examples of the code generation process. We have found that certain features of a language like subprograms, case differentiation constructors and symbolic identifiers are important for a direct mapping of the design objects onto the target language. In the case of control-oriented languages like the "Modicon State Language" or structured text according IEC 1131-3 this is exceedingly simple to do. Assembler-like languages which include in essence all current controller dialects as well as three languages of the IEC 1131-3, require much more effort. Fig. 4 illustrates a simple realization with function blocks where efficiency of the code depends on how much the target 
control supports the processing of function blocks. The application of special compilers might therefore be worthwhile.
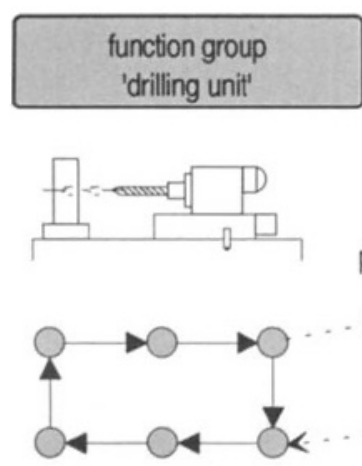

sequence

state graph

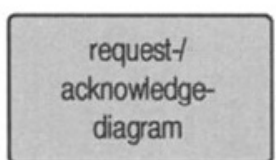

\section{drill}

pockethole
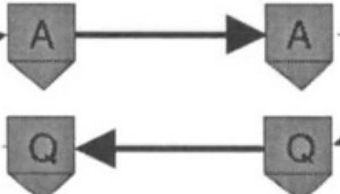

pockethole

finished start

feed feed finished
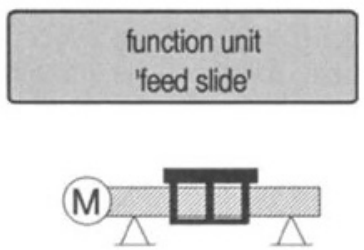

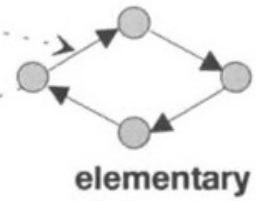

Figure 4 Sequence and elementary state graph synchronized by requests (A) and acknowledgements (Q) $(104343 \mathrm{e})$
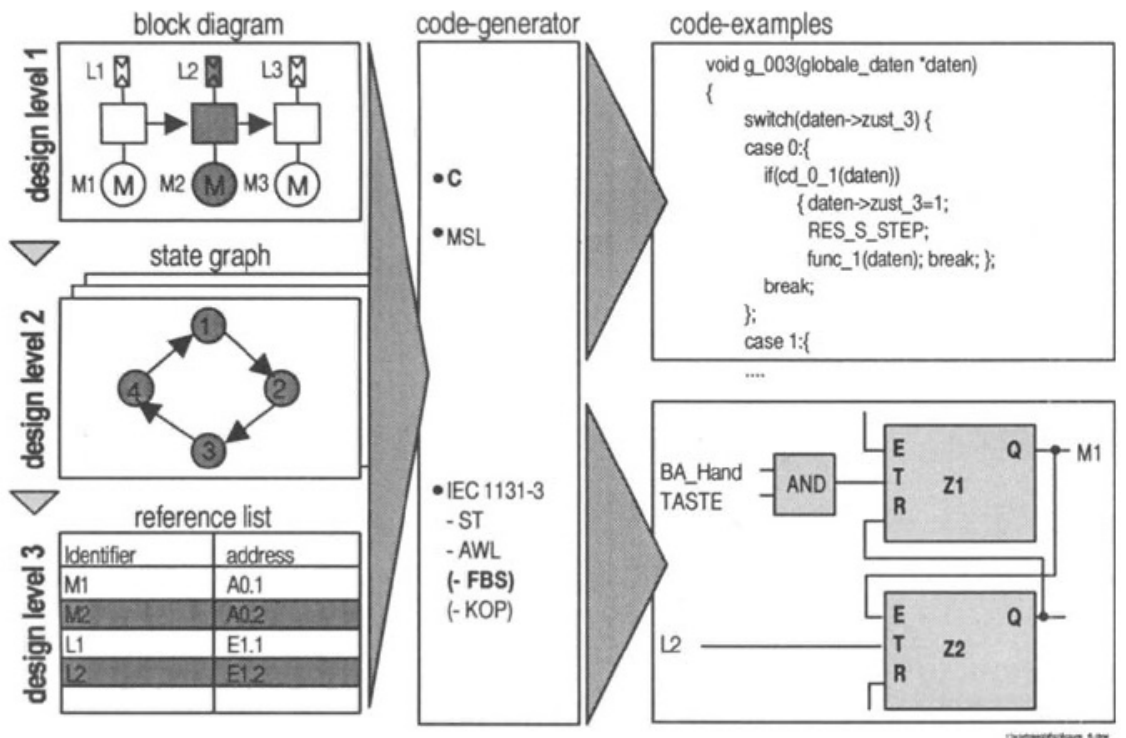

Figure 5 Concept of code generation (104344e) 


\section{CASE-TOOL ASPECT FOR SUPPORT OF CROSS- DEPARTMENTAL CONTROL PROGRAM DEVELOPMENT}

To a large part the methods and descriptions mentioned in chapter 3 and 4 meet the requirements placed in the beginning of this paper. The introduction of a computer-aided tool promises additional benefits (Lutz, 1995) because

- the employee is relieved of routine work,

- data is kept consistent and

- the current isolation of today's CAD systems can be partially abolished.

Important requirements for such a tool include

- support for all three design levels (general diagrams, functional descriptions, detailed descriptions),

- facilitates continuous progress throughout the project,

- uniform and consistent administration of entered data,

- simple and intuitive user interface,

- configurability by the user,

- extensibility,

- broad applicability, and

- possibility for multiple access.

Fig. 6 shows the structure of the prototype developed at the ISW, which fulfills the mentioned requirements for the most part. In particular the integrated project data base ensures relevance and consistency of data. The unified structuring allows the integration of further function modules in ASPECT.

\section{CURRENT RESEARCH ON REUSE}

Our current research work attempts to increase the efficiency and quality of software by specific and systematic reuse of designs, based on the state graph method. Reusable design provides the following benefits:

- Lower maintenance time and cost because only a few modifications have to be maintained even if a large number of applications are in operation.

- Less faulty and more stable designs, because faults are detected early due to repeated application of control software modules.

- Improved productivity because the know-how of qualified personnel is incorporated.

- Good and well established design examples make for an additional training effect that is especially beneficial for new personnel.

The present object-based modeling concept and the support by ASPECT create a basis for a systematical software development. Design levels and description methods provide the possibility to copy complex design objects which are congruent to mechanical subsystems from existing applications and to reuse them as software design modules. 


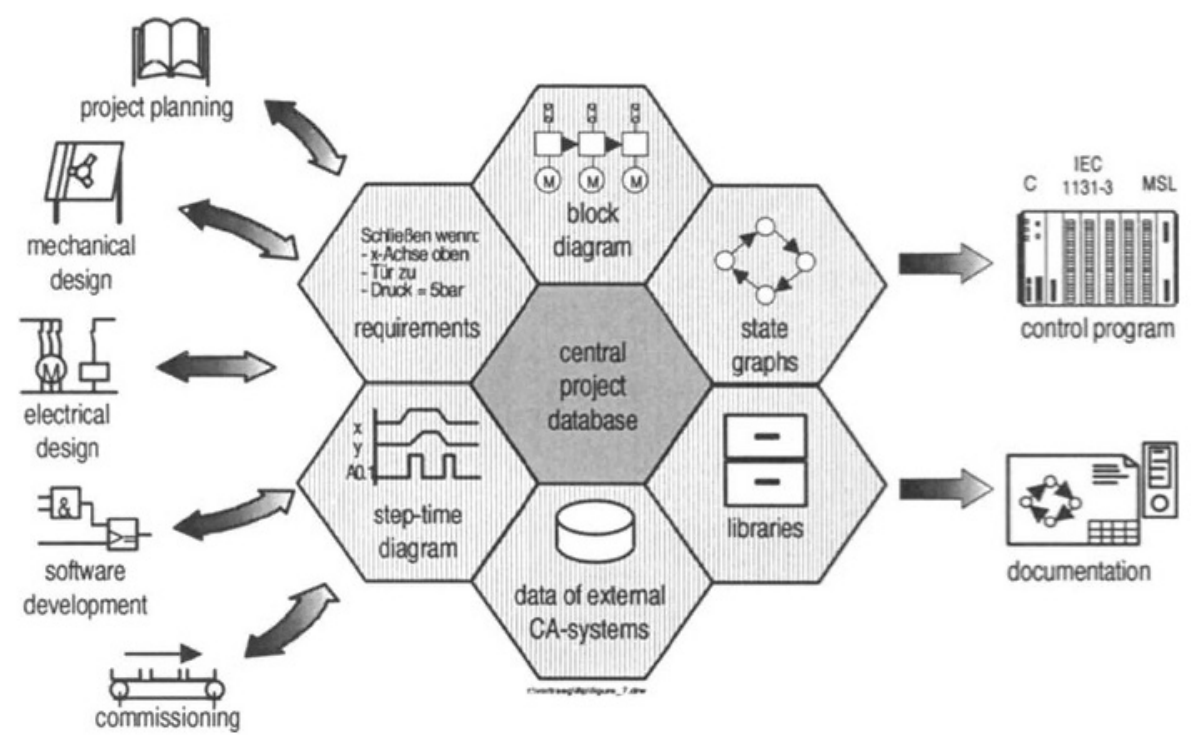

Figure 6 Modules of the CASE-Tool ASPECT (104 346e)

But systematic reuse for practical applications exceeds the „copying from application A and inserting in application B“. It requires a defined procedure with additional descriptions. So software development becomes a systematic configuration with parameterizable modules which are administrated in libraries. This results in the following features (see also Fig. 7):

- For the administration in libraries the function objects have to contain information details (reuse information) in addition to the software design. Thus a successful search is possible in an abstruct marner, without knowing the design details. Such information includes the specification on design level 1, list of hardware equipment (actuators and sensors) and the abstract service interface presented to the outside.

- Function objects have to be configured for the application when extracted from the library. Configurable elements are stored within the components as place holders. Place holders include identifiers (of design objects, states, components, variables,..) or comments. For the assignment of values or texts to place holders, function objects have to be represented by corresponding templates.

- By connecting the interface symbols (orders and acknowledgments) the function objects are integrated in an existing application. Since these interface symbols postulate specified counterparts (corresponding client and server functionality), they can, under certain circumstances, be searched for and connected by computer. So the configuration is partially automated.

- Objects of all design levels and of any complexity have to be specified and administered in the library. This includes simple binary sensors as well as complex hierarchical function groups (e.g. drilling units) with subordinated function units and their sensors, actuators and 
function descriptions (e.g. sequence and elementary state graphs). Furthermore, we need to examine how subfunctions (e.g. subgraph 'motor acceleration') can be defined and administered for repeated application.

- In order to classify modifications to function objects, the object-oriented principle of 'inheritance' has to be applied within a class hierarchy. Through inheritance, variable declarations (data) and functions can be generally used for similar function objects and redundancies can be avoided. In contrast to textual object-oriented languages (e.g. Smalltalk), a graphical language for control applications requires additional mechanisms, which allow for the inheritance of data (variables within function objects), hardware (sensors and actuators with controller inputs and outputs) as well as graphical design descriptions (e.g. state graphs).

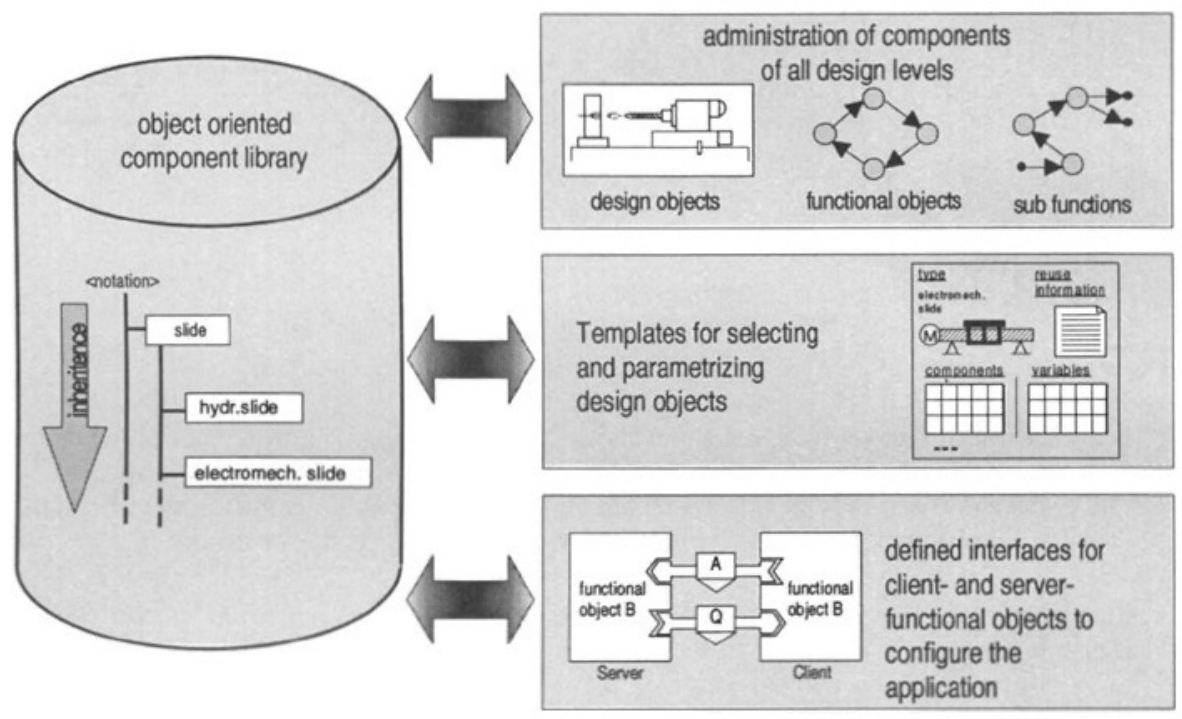

Figure 7 Systematically reuse of software design (104 345e)

The implementation of the above mentioned features is the subject of a current research project sponsored by the German Ministry for Education and Research, which is conducted in cooperation with two mechanical engineering firms and two software enterprises.

\section{SUMMARY}

With the current approaches to the development of machines and systems, the weak points of software engineering have been demonstrated. Strictly sequential procedures and poor information exchange between the departments of an enterprise are typical. An improvement can be achieved by a parallel procedure, the use of widely understandable description methods, a higher degree of reuse of existing design objects and the use of supporting tools. 
The development process has been divided into three design levels "general description", "functional description" and "detailed description". The usage of appropriate description forms allows for an improved project development time. The descriptions contain all information which is needed to generate the control code automatically by means of suitable compilers. The development engineers are therefore no longer compelled to take care of control hardware related details in early phases of a project.

This procedure is efficiently supported by a modular and open CASE tool, which makes the development of control functions easier through the use of graphical editors and also integrates all departments involved in the project through a central project data base. For this purpose the ISW developed the tool ASPECT as a prototype.

Current research work at the institute aims in particular to further improve the support for modeling and reuse of machine control software, by using object-oriented techniques.

\section{REFERENCES}

Storr, A., u.a.(1994) Simultan zur SPS-Software - Neue Ansätze zur effizienten SPSProgrammierung. Elektronik 23, 124-136.

N.N., IEC 1131-3: Programmable Control, Part 3: Programming Languages.

Herrscher, A., Grimm, W., Storr, A., Reichenbächer, J. (1991) Systematische Softwareerstellung für Steuerungen. In: Tagungsband zum FTK '91, Stuttgart 1.-2.10.1991, 52-58. Springer-Verlag, Berlin, Heidelberg, New York, Tokyo.

Pritschow, G., u.a. (1988) Studie über mögliche Beschreibungsformen bei der Softwareerstellung und Dokumentation. VDW-Forschungsbericht 1010, Frankfurt.

Fleckenstein, J. (1987) Zustandsgraphen für SPS - Grafikunterstützte Programmierung und steuerungsunabhängige Darstellung. ISW63. Springer Verlag, Berlin, Heidelberg, New York, Tokyo.

Otto, H.-P. (1992) Zustandsgraphen - Eine Einführung in die Methode mit Beispielen. Druckschrift des Arbeitskreises "Lastenheft für ein SPS-CASE-Tool", Nürnberg.

VDI-Richtlinie 3260 (1977) Funktionsdiagramme von Arbeitsmaschinen und Fertigungsanlagen. Beuth-Verlag, Berlin, Köln.

Pritschow, G., u.a. (1994) Interdisciplinary Models and Descriptions for the Program Development for PLCs. Production Engineering Vol. II/1. Hanser Verlag, München, Wien, New York.

Weck, M., Kohring, A. (1991) Die Bedeutung der Anlagespezifikation für die Entwicklung von SPS-Software. In: Pritschow, G., Spur, G., Weck, M. (Hrsg.): Maschinennahe Steuerungstechnik in der Fertigung. Hanser Verlag, München, Wien, New York.

Lutz, R. (1995) Systematische Softwareerstellung im Maschinenbau mit dem CASE-Tool ASPECT. In: Software-Entwicklung: Methoden, Werkzeuge, Erfahrungen '95;

6. Kolloquium 12.-14. September 1995, Technische Akademie Esslingen, Ostfildern. 


\section{BIOGRAPHY}

Dipl.-Ing. T. Brandl has worked at the ISW as electrical engineer since 1991. He carried out various research and development projects in the area of control technology, mainly for PLCcontrolled special purpose machines. Currently he is developing a tool to present the technical documentation as an „electronic manual“. Since 1996 he has been head of the group „Software Engineering and Diagnosis" at the ISW

Dipl.-Ing. R. Lutz After receiving his degree in mechanical engineering at the University of Stuttgart in 1993, he began to work at the ISW in the group 'Software Engineering and Diagnosis'. His main research field is methods and tools for software engineering in control technology and he has made a major contribution to the design and development of the CASE tool ASPECT.

Within the joint research project MOWIMA, which is sponsored by the German Federal Ministry of Education and Research, he is currently working on the reusability of software by developing and using module libraries for machine and plant construction.

Dipl.-Ing. J. Reichenbächer started his career at the ISW in 1988 and was head of the group "Software Engineering and Diagnosis" from 1990 to 1995. One of the projects he managed during this time was the development of the CASE-Tool prototype ASPECT that is presented in this paper. In January 1996 he left the institute to build up a group for development of master control technology at Charmilles, which is a manufacturer of erosion machines. 